\title{
OS BASTIDORES DA PSICOTERAPIA: DESCRIÇÃO DE SENTIDOS E A SUPERVISÃO CLÍNICA NA ABORDAGEM FENOMENOLÓGICA HUMANISTA
}

\author{
The backstage of psychotherapy: sense's description and clinical supervision in the humanist phe- \\ nomenological approach
}

\author{
Los bastidores de psicoterapia: descripción de sentidos y la supervisión clínica en el enfoque \\ fenomenológico humanista
}

ANDrÉa de SouZa Túbero Rita Martins Godoy Rocha

\begin{abstract}
Resumo: A psicoterapia é um campo científico que se aprimora de maneira contínua, especialmente pelas atuais demandas que requerem a garantia do protagonismo e a autonomia aos usuários de saúde mental. Nesse contexto, a supervisão clínica e os instrumentos construídos a partir dela aparecem como um importante fator no processo de qualificar a prática e formar novos terapeutas. O presente estudo tem por objetivo geral analisar os relatos descritivos produzidos para a supervisão de estágio, que incluem os apontamentos da supervisora, e são tomados como versões de sentido, com o intuito específico de dar visibilidade ao processo de formação do(a) futuro terapeuta. Para tanto, inspira-se no método fenomenológico com fundamento qualitativo e descritivo, que destaca a dimensão compreensiva, intersubjetiva e intencional entre consciência e mundo vivido. O corpus de análise constituiu-se de vinte e um relatórios de descrição dos sentidos no encontro psicoterapêutico com um único paciente, durante o ano de 2017. Foram selecionados três encontros psicoterapêuticos para análise das versões de sentido neste ensaio, a partir dos critérios temporal e longitudinal, procurando dar visibilidade ao processo clínico, às intervenções terapêuticas gestadas no encontro entre psicoterapeuta-paciente-descrição de sentidos-supervisão, e seu impacto na formação clínica. Há, por fim, a ressonância de novas maneiras de existir para ambos, paciente e terapeuta.
\end{abstract}

Palavras-Chave: Supervisão Psicoterapêutica; Clínicas-Escola; Fenômenos e Processos Psicológicos; Psicoterapia; Fenomenologia.

\begin{abstract}
Psychotherapy is a research field in continuous improvement, mostly due to the current requiring demands on protagonism guarantee and autonomy to mental health users of the tool. In this context, clinical supervision and the instruments that have been built from it represent an important factor to the process of qualifying the practice and training new therapists. The present study aims to analyse the produced descriptive internship reports, including the supervision notes, which are taken as sense's versions, in order to draw visibility to the process of preparing future therapists. Therefore, there has been inspired by phenomenological method on a qualitative and descriptive basis in order to characterize a comprehensive, intersubjective and intentional understanding between consciousness and the living world. The corpus of the analysis consisted of twenty-one patients' sense description reports produced along individual counselling sessions during 2017. Three psychotherapeutics meetings were selected for analysis of the sense's versions in this study, based on the temporal and longitudinal criteria, in order to provide visibility to the clinical process, as well as to the therapeutic interventions generated during the sessions, embracing therapist-patient-sense description-supervision, and their impacts on clinical training. Last, there has been observed a resonance of new ways of existing, sprouting for both patient and therapist.

Keywords: Psychotherapy Supervision; School-Clinics; Psychological Phenomena and Processes; Psychotherapy; Phenomenology.

Resumen: La psicoterapia es un campo científico que se perfecciona de manera continua, especialmente por las actuales demandas que requieren la garantía del protagonismo y la autonomía a los usuarios de salud mental. En ese contexto, la supervisión clínica y los instrumentos construidos a partir de ella aparecen como un importante factor en el proceso de calificar la práctica y formar nuevos terapeutas. El presente estudio tiene por objetivo general analizar los relatos descriptivos producidos para la supervisión de prácticas, que incluyen los apuntes de la supervisora, y se toman como versiones de sentido, con el propósito específico de dar visibilidad al proceso de formación del futuro terapeuta. Para ello, se inspiró en el método fenomenológico con fundamento cualitativo y descriptivo, que destaca la dimensión comprensiva, intersubjetiva e intencional entre conciencia y mundo vivido. El corpus de análisis se constituyó de veintiún informes de descripción de los sentidos en el encuentro psicoterapéutico con un solo paciente durante el año 2017. Se seleccionaron tres reuniones psicoterapéuticas para análisis de las versiones de sentido en esta prueba, en base a los criterios temporales y longitudinales se busca dar visibilidad al proceso clínico, a las intervenciones terapéuticas gestadas en el encuentro entre terapeuta-paciente-descripción de sentidos-supervisión, y su impacto en la formación clínica. Hay, por fin, la resonancia de nuevas maneras de existir, brotando para ambos, paciente y terapeuta.

Palabras-Clave: Supervisión Psicoterapéutica; Escuela Clínica; Fenómenos y Procesos Psicológicos; Psicoterapia; Fenomenología.
\end{abstract}




\section{Introdução}

No campo da saúde mental, a Psicoterapia pode ser compreendida como uma ciência e uma arte "que se dedica ao alívio do sofrimento humano, decorrente de conflitos e desordens emocionais", conforme apontam Gomes e Castro (2010, p.83). Ciência por pautar-se na evidência dos próprios resultados, com o propósito de amenizar o sofrimento, e arte por envolver o manejo e o desempenho do terapeuta no conjunto epistemológico - teoria, técnica e métodos clínicos -, além de competências intersubjetivas, vivenciadas em singularidade pelo terapeuta. Trata-se, pois, de um processo interpessoal "que envolve psicoterapeuta e paciente por meio de contatos verbais e não-verbais, com o objetivo definido de auxílio às dificuldades emocionais do paciente, visando a sua própria integração à vida" (Boris, 2008, p.173).

$\mathrm{O}$ atendimento psicoterapêutico pode ser individual ou em grupo, para casais ou para famílias, e também pode assumir uma prática mais ampliada como, por exemplo, o atendimento à comunidade. No trabalho com os pacientes, além do recurso comunicacional, o terapeuta pode utilizar a expressividade corporal (dança, mímica, drama) e a arte (desenhos, pintura, modelagem) como instrumentos terapêuticos reveladores de significados. Tais manifestações são, num segundo momento, apreciadas num sentido vivencial, cognitivo e também comportamental (Gomes \& Castro, 2010).

No cenário da Reforma Psiquiátrica, ainda em curso, as inovações psicoterapêuticas aparecem como demandas importantes, no sentido de colocar em questão o conceito de doença mental, tradicionalmente engendrado em práticas manicomiais, que culminaram no estigma das pessoas que vivenciavam um sofrimento emocional. A doença mental, antes confinada aos manicômios, passa a ser compreendida como parte da condição humana e assim, adquire outro destino social. A Reforma Psiquiátrica brasileira foi inspirada na emblemática reforma italiana, cuja figura central é Franco Basaglia, que propõe a desinstitucionalização como forma de negação das práticas psiquiátricas tradicionais, e a construção de uma rede de atenção territorial às pessoas em sofrimento psíquico. Basaglia (1906/2010) propõe a parentetização da doença mental, inspirado pelos preceitos fenomenológicos, com o propósito de ocupar-se da pessoa em sua experiência concreta de sofrimento, resgatar sua singularidade, favorecendo sua individuação e seu protagonismo na vida.

Obrigado a colocar entre parênteses a doença, o diagnóstico, a síndrome que o etiquetou, pretende-se com isso conseguir compreendê-lo e principalmente, agir sobre ele, já que se encontra destruído muito mais pelo que se considerou acerca da doença e pelas medidas de segurança impostas a partir de tal interpretação (Basaglia, 1969/2010, p. 66).
No mesmo paradigma, a experiência de um novo modelo clínico em saúde mental tem início em ambiente acadêmico, no final da década de 1960, início dos anos 70, no Brasil, procurando superar o modelo hegemônico da atenção hospitalar e do consultório particular, chegando à comunidade. Como marco, temos o trabalho desenvolvido na Faculdade de Ciências e Letras (FFCL) da USP, por intermédio da disciplina Aconselhamento Psicológico, que introduz os fundamentos clínicos de inspiração fenomenológica, associados à Psicologia Humanista protagonizada por Carl Rogers, entre outros autores. Os cursos de Psicologia que atualmente possuem clínicas-escola com o propósito de ensinar e supervisionar a atuação de terapeutas em formação são, ao mesmo tempo, tributários e herdeiros dessa experiência de implementação de Serviço de Atendimento Psicológico (SAP) no Brasil (Rosenberg, 1987).

Esse novo modelo clínico em Psicologia, que se consolida no Brasil na década de 1980, tem como referencial a inversão de ênfases inspiradas no método fenomenológico em diálogo com a proposta de Rogers: substituição do problema para o foco na pessoa em atendimento, do instrumental de avaliação para a relação conselheiro-cliente e do resultado para o processo (Rosenberg, 1987).

Tomando como referencial a centralidade da pessoa em sofrimento para o processo terapêutico e seu protagonismo na construção de possibilidades concretas de vida, o presente estudo, na abordagem fenomenológico humanista, se insere no esforço de descrever e compreender a experiência do psicoterapeuta em formação, que encontra no momento da supervisão clínica um importante espaço facilitador (Boris, 2008).

Neste trabalho, as práticas psicoterápicas e as supervisões dela decorrentes estabeleceram-se com base na Fenomenologia, pautada em saberes oriundos do campo filosófico, que revisitam a construção do saber sobre a pessoa em sofrimento mental (Basaglia, 2010). O método fenomenológico, desenvolvido por Edmund Husserl (1859-1938), apesar de circunscrito ao campo ontológico e filosófico, em virtude de sua amplitude e singularidade, inspirou as correntes da clínica fenomenológica, traduzindo esforços de parentetizar a própria ideia de objeto, do determinado, do mundo natural, no seguinte sentido: ao suspendermos todos os fatos, o que aparece? Trata-se de um esforço de "voltar à coisa mesma”, ou seja, o objeto deixa de ser intuído como um objeto de fato, para existir como um objeto intencional, tal qual se manifesta à pessoa, segundo modos distintos de doação (Husserl, 1913/2006).

Nesse momento, é fundamental a descrição em detalhes, atentar para nuances e retornar à coisa/pessoa, sem buscar uma interpretação prévia. O mais acertado, segundo Amatuzzi (2009, p.95), seria falar de "redução a: redução ao que imediatamente se apresenta. (...) A isso que se apresenta chamou-se fenômeno. Trata-se do aparecer das coisas".

Após o esforço da parentetização, ensaia-se uma 
saída da suspensão junto à possibilidade de identificar um sentido mais próximo ao eidético no encontro, o qual carrega um significado proeminente (Rocha, 2015). Porém, por se tratar de um processo permanente e horizontal, em que o método é sempre colocado em perspectiva, aquilo que parecia dado e interpretado, volta a ser parentetizado, em um movimento contínuo de significação no encontro terapêutico (Moreira, 2013).

Sob essa perspectiva, o processo terapêutico e a pesquisa fenomenológica, partem da indissociabilidade entre homem e mundo, homem e outro, inspirados na premissa da intencionalidade, em que toda consciência é consciência de algo; não há ser no vácuo, não há sentido sem o mundo e o outro, sem um tempo e um espaço (Husserl, 1926-38/2012). Portanto, trata-se de um paradigma que rompe com a dualidade e factualidade neutra da ciência, tradicionalmente vinculada aos fundamentos positivistas e naturalistas.

$\mathrm{Na}$ abordagem psicoterápica com enfoque fenomenológico são particularmente importantes para a formação de futuros psicoterapeutas os relatos de experiência e estudos de caso, apresentados a partir de psicoterapia individual ou de grupos (Moreira, 2013). As pesquisas permitem reconhecer as dificuldades na "conquista" das condições para a mudança psicoterapêutica, que passa necessariamente pela relação psicoterapeuta-cliente, como via de acesso à expressão da experiência da(o) paciente no curso do próprio processo psicoterapêutico (Amatuzzi, M. M., Solymos, G. M. B., Ando, C., Bruscagin, C. B. S., \& Costabile, C. , 1991; Boris, 2008; Moreira, 2013). Nesse sentido, o psicoterapeuta, com sua presença, é entendido como instrumento do processo:

O contato com o cliente faz nascer em mim a necessidade de uma resposta; mas é uma resposta que tenho que dar em minha vida pessoal, muitas vezes fora do consultório, e não necessariamente para ele. Para ele o que existe é uma parte dessa resposta: a vontade de ouvir, o interesse em ouvir com cada vez maior precisão e profundidade o que ele tem a dizer. Constatei que quando isso ocorre, a fecundidade terapêutica do encontro é muito grande, e a minha condição de objetividade é também maior, isto é, o cliente se sente mais bem compreendido naquilo que realmente se passa com ele, podendo explicitá-lo ou dizê-lo melhor (Amatuzzi et al., 1991, p.5).

Pensar o(a) psicoterapeuta como instrumento do processo, conforme propõe Amatuzzi (2010), nos remete novamente à Rogers, mas, sobretudo à fase experiencial de sua obra que revitaliza o sentido de experiência num diálogo profícuo com a Fenomenologia, focalizando a experiência da relação vivida pela pessoa em atendimento, pelo(a) psicoterapeuta e por ambos. Em Tornar-se pessoa, Rogers (1975, p.27) nos apresenta o que aprendeu "no decurso de milhares de horas" que passou trabalhando intimamente com "indivíduos que apresentavam perturbações pessoais". Dentre os aspectos que considera fundamentais para a mudança psicoterapêutica, Rogers retoma também nesta obra as três atitudes facilitadoras do terapeuta no processo relacional: a congruência que se refere à capacidade do terapeuta assumir-se autenticamente nos próprios sentimentos, com foco no cliente e se for pertinente ao processo clínico comunicar tal sentimento, facilitando assim o processo do(a) cliente em assumir-se também; a compreensão empática que traduz a capacidade do(a) terapeuta estar sensível aos sentimentos do cliente, buscando uma compreensão do que significa para a pessoa o que ela está dizendo, a partir do referencial dela, fazendo ressoar em si o outro, sem assumir o mundo do outro, mas permanecendo junto; e por fim, a consideração positiva incondicional como a atitude de receber os sentimentos e vivências do(a) cliente, conforme se apresentam no encontro, sem restrições valorativas ou ainda receio de tais sentimentos, temendo misturar-se ou ser enredado por eles (Rogers, 1975).

A abordagem fenomenológica reconhece a importância da experiência emocional básica entre os seres humanos numa relação terapêutica, e sustenta uma epistemologia que consubstancia a clínica, inicialmente inspirada pela postura fenomenológica de parentetização e intencionalidade, em diálogo com a fase experiencial de Rogers (1975) e a leitura relacional das atitudes facilitadoras, aprimoradas por psicoterapeutas contemporâneos (Rosenberg, 1987; Amatuzzi, 2010; Moreira, 2013).

A Fenomenologia como método permite olhar para as intuições e presenças, não de forma objetiva, mas sob o ângulo do sentido que os fenômenos têm para os sujeitos que os vivem (Giorgi, 2008). Assim, o esforço de presentificação do sentido ocorre na sessão terapêutica e pode ocorrer depois, durante a supervisão. Trata-se do mesmo esforço de apreensão e presentificação do sentido, embora a situação seja diferente. O esforço compreensivo de explicitação sucessiva dos sentidos das sessões em supervisão, como algo vivido e presente, habilita o terapeuta em sua tarefa nas próximas sessões (Amatuzzi, 2010).

O espaço de supervisão, outrossim, aparece como potência formativa da Psicoterapia, que além de transmitir os ensinamentos básicos, conforme a abordagem, possibilita que:

(...) cada estagiário olhe para dentro de si, para a relação que estabelece com seu cliente e para o vínculo que desenvolve com seu supervisor. Treinar em grupo é inserir o terapeuta iniciante em um mundo de relações reais e presentes onde ele pode avaliar-se, espelhar-se e se encontrar com o outro. É prepará-lo para a relação profunda que se estabelece entre terapeuta e cliente (Tavora, 2002, p.121). 
Boris (2008) refere que a grande dificuldade dos processos de supervisão, sobretudo em clínica-escola, é a semelhança e, ao mesmo tempo, a diferença que ela tem com a própria psicoterapia. A supervisão não se propõe a ser um espaço de intervenção do supervisor nas questões pessoais e íntimas dos psicoterapeutas iniciantes. Contudo, sem a real compreensão do vínculo entre seus temas existenciais e os processos que os acompanham, a supervisão corre o risco de se tornar um estudo teórico-técnico distanciado.

Na epistemologia fenomenológica, que inspirou o modelo clínico, bem como a pesquisa fenomenológica, há uma mudança na relação com o “objeto”. O ser humano não é compreendido como resultante de uma série de coisas, mas como o iniciante: "Este homem atual, presente, desafiado, interpelado, em movimento, é o que encontra as questões de sentido. (...) É na decifração de suas questões de sentido (caminho) que o homem pode se instaurar em sua atualidade" (Amatuzzi, 2010, p.11). Trata-se, portanto, de uma outra atitude científica que implica conceber a relação humana como reciprocidade que brota no ato da relação, e o conhecimento como um aspecto da interação humana com o mundo (Buber, 2001).

Esforços compreensivos acerca dos sentidos que aparecem na interface entre Psicoterapia e supervisão podem ser encontrados em Amatuzzi et al. (1991) que se reuniu em grupo para analisar coletivamente os sentidos de suas sessões, além das experiências de sentido no trabalho em saúde mental com grupos terapêuticos contempladas por Tavora (2002), Boris (2008) e Moreira $(2013 ; 2016)$.

Conforme Moreira (2016), versões de sentido, produzidas por terapeutas em formação, são utilizadas na prática educativa, na assessoria de trabalho com grupos e também vem sendo adotada na formação e supervisão de alunos, bem como no âmbito de pesquisas. Aparecem como um instrumento usado em supervisões para favorecer o processo de análise pós-presencial com o paciente. Configura-se como um meio de retomar e ampliar os sentidos vividos durante a sessão, e favorecer a interlocução, ampliando a relação entre paciente-terapeuta, para paciente-terapeuta-supervisor (Amatuzzi et al., 1991; Boris, 2008; Moreira, 2013, 2016).

Boris (2008) considera a versão de sentido como uma radiografia fenomenológica do encontro, que permite falar dele de forma viva e atual, como da primeira vez, explicitando detalhes do vivido. Deste modo, busca-se, através da versão de sentido produzida após o atendimento clínico, entrar em contato com os sentidos originados no e durante o encontro entre terapeuta e paciente, procurando clarificar a percepção do terapeuta em busca da compreensão do significado (Boris, 2008).

Desimpregnar-se é parte do processo que nos coloca no setting, diante da pessoa em atendimento, numa relação mais horizontal, bicentrada, que valoriza a autenticidade do terapeuta e a capacidade de de- senvolvimento do paciente, em detrimento do interesse diagnóstico. Há um esforço no sentido de explorar dois mundos fenomênicos, "fazendo-os interatuar em benefício do cliente através da criação de novos significados a partir do espaço experienciado por ambos” (Moreira, 2013, p.28).

As versões de sentido promovem, portanto, uma continuidade do processo de significação na supervisão, e também neste estudo, uma vez que favorecem o prolongamento do vivido no encontro terapêutico, com novas buscas de intervenções e possibilidades analíticas. Esse instrumento é utilizado neste trabalho com o propósito de dar visibilidade ao processo terapêutico, às intervenções terapêuticas gestadas no encontro entre terapeuta-paciente-descrição de sentidos-supervisão, e à formação clínica do terapeuta em supervisão, buscando compreender os significados vividos neste encontro, atualizando-os e criando mais significados.

Tomando, portanto, a descrição de cada encontro com o paciente como versão de sentido, o objetivo deste artigo é apresentar um recorte da pesquisa com base em vinte e um relatos descritivos e longitudinais produzidos para a supervisão de estágio, junto aos apontamentos da supervisora, na busca por dar visibilidade ao processo de formação do(a) futuro(a) psicoterapeuta na abordagem fenomenológica humanista.

\section{Metodologia}

O presente estudo está pautado numa epistemologia qualitativa que se viabiliza pela descrição detalhada dos passos no processo de pesquisa. A Fenomenologia assim como inspirou e influenciou a prática psicoterapêutica (Amatuzzi, 2009; Gomes \& Castro, 2010; Moreira, 2013), também contribui como fundamento para práticas de pesquisa empíricas, baseadas em um modelo compreensivo (Goto, 2008; Giorgi, 2008; Barreira \& Raniere, 2013).

O método fenomenológico inspira e fundamenta estudos empíricos, especialmente pelos conceitos de generatividade e intencionalidade de Husserl, que sustentam uma indissociabilidade intencional entre o homem e mundo, com ênfase nas relações de intropatia, ou seja, de uma co-presença humana em um passado, presente e futuro histórico (Husserl, 1926/38, 2012). Desse modo, não se busca fatos, mas a parentetização dos fatos. Não se pauta, pois, nas verdades que tendem a hipóteses iniciais e nem na neutralidade, uma vez que a realidade não é negada (Husserl, 1907/1958). Direciona-se a busca pelo retorno ao intuído, podendo surpreender-se com o que do fenômeno emerge.

Desse modo, um dado "objeto de estudo" requer a compreensão do seu aspecto generativo, temporal e intencional presente entre seus interlocutores, partindo assim, de sua premissa intersubjetiva, e dos significados que integram um dado processo e contexto (Rocha, 2015).

A partir de uma ressignificação da empiria e da correlação entre consciência pura e mundo da vida, 
desde a década de cinquenta do século passado, o método fenomenológico, historicamente inserido no campo filosófico, começa a inspirar a análise de pesquisas empíricas. A inserção na Psicologia, especificamente, vem sendo observada nas últimas décadas do século $\mathrm{XX}$, num movimento que procurou estabelecer uma ciência humana pautada na compreensão da experiência vivida, demandando, para isso, reformas metodológicas; dentre as quais se destacaram a influência da parentetização e da Fenomenologia na pesquisa (Giorgi, 1978; Gomes \& Castro 2011; Rocha, 2015).

Trata-se de uma nova concepção de ciência, de pesquisa, de investigação e também de prática, que preconiza uma transformação mais global, em que a ação concreta, a psicoterapia, por exemplo, pode ser vista também como pesquisa, como investigação.

A pesquisa de inspiração fenomenológica em Psicologia tem por objetivo, portanto, uma aproximação com o vivido e a expressão do que está contido nesse vivido como significado potencial, face a uma indagação que move o pesquisador(a) terapeuta. Interessa-nos mostrar e compreender como se dá o processo de formação do(a) futuro terapeuta em supervisão, a partir do vivido. E o que é o vivido? É a experiência imediata; descrita antes que tenhamos elaborado conceitos (Amatuzzi, 2010).

\section{Considerações éticas}

Este trabalho de pesquisa, aprovado em 2018 pelo Comitê de Ética em Pesquisa da instituição de ensino, sob registro 80007317.9.0000.5383, não tratou de questões que possam identificar o paciente ou mesmo comprometê-lo pessoal, fisicamente e profissionalmente. Seu propósito foi compreender o processo de formação do(a) futuro(a) terapeuta, em supervisão, a partir de relatos descritivos de seu atendimento. Tais relatos são de autoria de alunas em estágio clínico, realizado em dupla. Referem-se à descrição da relação que se estabelece no setting terapêutico entre as terapeutas em formação, e Paulo, nome fictício, tal como foi vivenciado. Interessa-nos, sobretudo, o diálogo intersubjetivo que acontece no encontro, no "entre", e as observações e orientações subsequentes da supervisora, relativamente à posição ocupada pelas terapeutas em formação durante os encontros.

Não houve outro contato direto com o participante, ex-paciente da clínica-escola, exceto para pedir-lhe o consentimento e informar-lhe sobre o estudo, de modo que lhe foi solicitada a assinatura do Termo de Consentimento Livre e Esclarecido (TCLE), conforme Resolução CNS 466/12 e suas complementares (Brasil, 2012).

\section{Corpus da pesquisa e de análise}

$\mathrm{O}$ presente estudo constitui-se com base na experiência de atendimento clínico realizado na Clínica Escola de uma Universidade no interior paulista, no período de abril a novembro de 2017, com um único paciente, Paulo, do sexo e gênero masculino, com a idade de 39 anos, inspetor escolar, encaminhado por uma dermatologista da rede pública de saúde, em virtude da manifestação de psoríase palmo-plantar. A recomendação de psicoterapia estava relacionada ao estresse vivenciado por Paulo que, de acordo com a médica, agravava sua doença autoimune. A escolha do paciente seguiu os critérios de inscrição para atendimento psicológico e a lista de espera da clínica-escola.

O corpus é formado por 21 relatos descritivos e longitudinais das sessões realizadas com Paulo, tendo como base as descrições/unidades de sentido construídas por duas terapeutas em formação, uma delas autora deste estudo, sob supervisão e orientação da co-autora na abordagem fenomenológica humanista. A pesquisa considerou inicialmente a totalidade das descrições produzidas pelas terapeutas em formação, durante o período de abril a novembro de 2017.

As descrições semanais de atendimento são uma exigência da disciplina de Estágio na abordagem fenomenológica humanista. O conteúdo de tais relatos independe e difere das informações contidas no prontuário do paciente que, depois de encerrado, foi arquivado sob a responsabilidade da clínica escola. A supervisão presencial do estágio obrigatório, por sua vez, também acontece semanalmente, em grupo de seis a oito alunos. Tais encontros tem por objetivo o acompanhamento sistemático dos atendimentos realizados. Após a sessão de psicoterapia com o usuário, a descrição de sentido era redigida para a supervisão semanal, que ocorria, logo no dia seguinte. Durante a supervisão, recebíamos a descrição da sessão anterior, com os apontamentos da supervisora, por escrito, no próprio relatório, que passava a incorporar também sua voz, além das nossas, alunos em formação, e do paciente, tal como vivenciado por nós.

Trata-se, portanto, de um estudo que procura percorrer a seguinte pergunta: a qual compreensão do processo terapêutico a análise das descrições de sessão e a supervisão nos conduz? O interesse é a versão de sentido, algo distinto do relato "realístico e objetivo" do que ocorreu durante a sessão em sua materialidade, mas que pode ser compreendido a partir dele, ressignificando o encontro psicoterapêutico pelo processo de supervisão clínica.

O exame analítico dos relatos descritivos de sentido segue os seguintes passos:

a) Leitura exaustiva dos relatos descritivos sobre os encontros terapêuticos com o paciente;

b) Análise descritiva: apresentação descritiva dos relatos, de modo a dar visibilidade ao processo, apresentando a polifonia entre paciente, terapeuta e supervisora;

c) Análise compreensiva das versões de sentido: momento de saída do parêntese e de busca de outros sentidos em diálogo com tendências teóricas para a formação do terapeuta. Para tanto, apresentamos três sessões selecionadas a partir dos critérios temporal e longitudinal, cujas descrições dão visibilidade ao processo terapêutico e de supervisão, para apresentação 
analítica e discussão dos resultados.

\section{Resultados Análise do Corpus}

Escrever sobre o primeiro atendimento clínico supervisionado numa perspectiva fenomenológica é mobilizar uma nova disposição. A adoção do método fenomenológico no encontro na clínica-escola, e também na pesquisa, exige do(a) recém-nascido(a) terapeuta-pesquisador(a) o esforço de se despir de automatismos, abdicar da lente habitual utilizada para olhar para si mesmo(a) e para o mundo, sobretudo, porque ela oferece as mesmas leituras-respostas, num lugar de acomodação. Adotar uma perspectiva fenomenológica implica nos desimpregnar por meio da árdua tarefa metodológica de "olhar de novo" e de novo e de novo, para talvez começar a tatear e então, "voltar as coisas mesmas", como nos inspira Husserl (1913/2006).

E é esse mesmo o propósito da pesquisa fenomenológica: voltar ao vivido, "não negando as elaborações que fazem parte dele, mas colocando-as provisoriamente entre parênteses, para revivê-las depois, à luz daquela fonte primeira” (Amatuzzi, 2010, p.55).

A análise que segue, traz dois momentos distintos e complementares. Em seu aspecto descritivo, ela se apresenta com recorte do que foi trazido para o encontro pelo paciente e o que foi vivido no encontro com ele e, na sequência, durante a supervisão, referida àquele encontro. Tal descrição assume um caráter mais pessoal, em primeira pessoa do singular, e também traz a voz do paciente e da supervisora com o propósito de dar visibilidade a um processo dinâmico, que não está centralizado nem nas terapeutas em formação, nem na supervisora, e nem no paciente, embora não percamos de vista que ele é o foco em nossa clínica. Tratou-se e trata-se, mais uma vez, do esforço de captar o que a pessoa quis dizer, mais do que o que ela literalmente disse (Amatuzzi, 1991). Não se trata, portanto, de uma simples reprodução do que foi dito durante o encontro terapêutico e como olhamos para ele na supervisão. Trata-se ainda aqui, desse mesmo esforço em busca do sentido.

Em seu aspecto compreensivo, a análise está referida a um segundo momento do método fenomenológico, quando saímos do parêntese e nos lançamos em busca de outros sentidos em diálogo com os autores. A análise compreensiva do que aconteceu reassume a primeira pessoa do plural, porque se trata de uma reflexão sobre experiências compartilhadas pelas terapeutas em formação, paciente, supervisora e colegas que estiveram conosco em grupo de supervisão, durante o referido período. O que moveu este trabalho de pesquisa, cujos sujeitos, grosso modo, são as próprias pesquisadoras, terapeutas em formação e supervisora - também orientadora do trabalho-, foi a intenção de manter vivo o sentido da gestação de um processo terapêutico.

O primeiro encontro com o paciente era e não era uma novidade, especialmente, por já termos vivido o contexto clínico como pacientes e também, pelo processo de ensino, anterior a prática. Tratava-se, entretanto, de um novo intento na postura de terapeutas, e para além das expectativas e conceitos que se passavam na consciência intelectiva, seria o momento da experiência por ela mesma. Havíamos, naquele primeiro momento, nos esforçado, procurando identificar "a queixa" do paciente e, aparentemente, tínhamos alcançado o propósito, associando-nos ao lugar de funcionalidade na condução do processo. O paciente, por ter sido visto, ouvido, também sai de outra maneira do encontro conosco: “(...) acho que vai ser muito bom para mim. Eu sou muito nervoso. (...) Já falei, qualquer dia a coisa explode. (...) Eu posso até me prejudicar e ser mandando embora. Já pensou se eu sou mandado embora?"

$1^{\circ}$ Encontro: 27 de abril de 2017

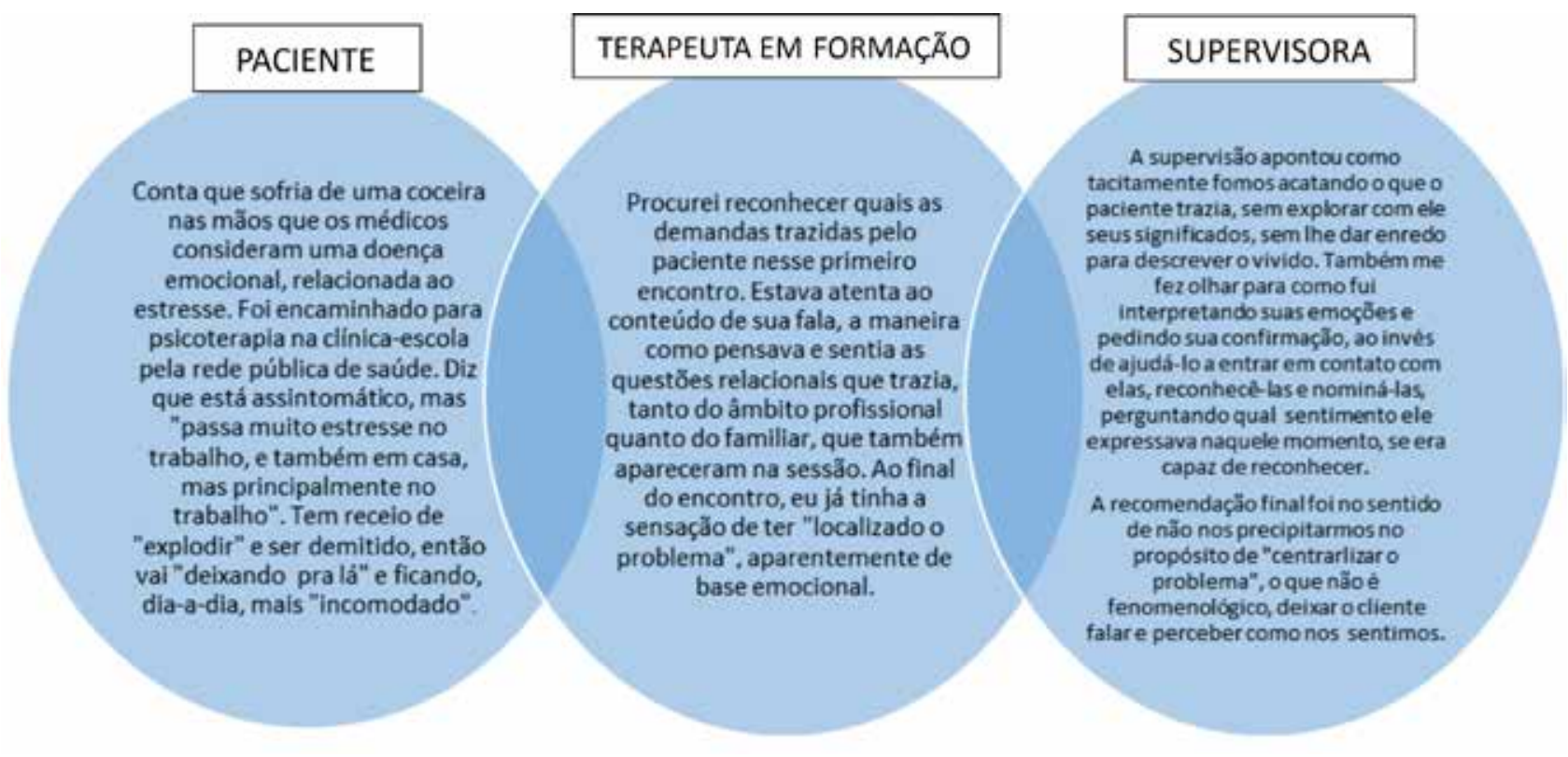


A primeira supervisão, ao contrário do primeiro encontro com o paciente, foi surpreendentemente frustrante. Os apontamentos e a devolutiva da supervisora mostravam que o que havíamos considerado um primeiro atendimento bem-sucedido, estava longe do que chamamos de "encontro" na abordagem fenomenológica humanista. A imagem que supervisora traz revela exatamente essa distância entre terapeutas e o paciente: “(...) de que adianta estarem lá, além do arco-íris, em busca do pote de ouro, se seu paciente não está junto de vocês? Seu paciente não está onde acham que ele está, não!”

A supervisora estava se referindo à postura resolutiva e distante da pessoa em atendimento, mais preocupada em identificar, reconhecer a queixa, e também às tentativas de hermenêuticas apressadas, fugidias ao tempo de Paulo, com a intenção de mostrar eficiência não só a ele, mas também a ela, afinal, o encontro deveria ser detalhadamente transcrito por nós. Sentíamo-nos criticadas e confusas durante a supervisão, ao mesmo tempo que já tateávamos, meio às cegas, algo que tinha menos a ver com o que havia sido dito pelo paciente, e mais com a maneira de estar - ou que evitávamos estar junto de alguém.

Revisitar este primeiro encontro, traz de volta o receio de sermos ou não aceitas pelo paciente, e a maneira como procuramos responder à nossa insegurança no encontro: mostrando ao paciente nossa "resolutividade", ou seja, o quanto poderíamos ser eficientes e capazes de dar conta de suas demandas.

Amatuzzi diz que o que "acontece ao terapeuta" - quando ele está atento ao que sente no encontro com a pessoa em atendimento - pede uma resposta, um trabalho, um cuidado consigo, que não se realiza ali, naquela relação, embora nela se mostre: "O contato com o cliente faz nascer em mim a necessidade de uma resposta; mas é uma resposta que tenho que dar em minha vida pessoal, muitas vezes fora do consultório, e não necessariamente para ele" (Amatuzzi et al., 1991, p.5). Ao escrever somos capazes de reconhecer que não pudemos admitir que houve desconforto no primeiro encontro em dupla com o paciente. E se não nos permitimos perceber e aceitar o que sentíamos no encontro, não pudemos sequer pensar em comunicar ou não esse desconforto e estranhamento, transitar por ele, sentir se favoreceria ou não o processo que estava tendo início ali. Não por acaso, estávamos ocupadas demais com o conteúdo que o paciente trazia. Foi na supervisão que esse desconforto apareceu, provocado pela supervisora. Nesta releitura do primeiro encontro, é perceptível a fragilidade de sustentar nossas presenças favorecendo o vínculo, e a tentativa de compensar isso com "eficiência interpretativa", do tipo: "sabemos o que você está sentido". A imagem intencionada é a de um carro com pneus descalibrados e a tentativa de rodar enchendo apenas os pneus do lado esquerdo - claro, o do motorista! Quem dá o tom do processo terapêutico? O paciente? As terapeutas? A relação? Quais condições devem estar presentes e persistir para que haja mudança?

A primeira supervisão apresentou-nos um outro lugar no setting, que coloca as terapeutas como instrumento da efetividade do vínculo terapêutico. Isso foi bem confuso, possivelmente, porque tal lugar contradizia o lugar do(a) terapeuta que tínhamos idealizado, em outras palavras, pré-concebido. Mais do que a doença que trouxe Paulo à psicoterapia, e não ocupou mais que três ou quatro minutos de nosso primeiro encontro, era preciso parentetizar a ideia que fizemos de nós mesmas como terapeutas, e nos abrir para o encontro como éramos. Com proatividade, resolutividade, evitamos o desconforto, o vivido e, por consequência, o encontro. Esse é o acontecimento de que Amatuzzi et al. (1991) nos fala, e que pede uma resposta não para o paciente. O ímpeto de encontrar Paulo, o reconhecimento das terapeutas como instrumento da psicoterapia, assim como a maneira que entramos em contato com o paciente, como o escutamos e o percebemos, como observamos o que sentimos enquanto estamos com ele, fazem toda a diferença no processo e é, portanto, parte do método.

Para que houvesse encontro era preciso encarar o desconforto que emergiu, não no setting com o paciente, e sim na supervisão e também em nossas psicoterapias individuais.

Foi nesse primeiro encontro e na primeira supervisão que o conceito rogeriano de incongruência nos aconteceu. Vivemos a contraposição entra a experiência real, ali, e a imagem de self das terapeutas. Sobre o conceito de autenticidade na fase reflexiva da obra de Rogers, Moreira (2013) destaca que não é necessário, nem mesmo possível, o terapeuta assumir um modelo de perfeição. O importante é que ele esteja integrado, presente de forma genuína. Isto envolve reconhecer sentimentos desagradáveis e inadequados; se o terapeuta for capaz de assumir livremente esses sentimentos, transitar por eles, a condição de terapia é atendida.

Assim, para Rogers, no momento que o terapeuta encara seus sentimentos não enganando a si mesmo - e nem ao paciente -, tal atitude, mesmo que não seja comunicada, torna o terapeuta congruente e integrado à relação, desbloqueando o caminho da terapia. No contexto relacional, tratou-se de reconhecer e apreender a importância de retomar o encontro por ele mesmo, para além do que se tinha como resolutivo e do que se tinha compreendido como postura "ideal" de psicoterapeuta em nível conceitual, um exercício de retorno ao contato humano. 
10 Encontro: $14 / 08 / 217$

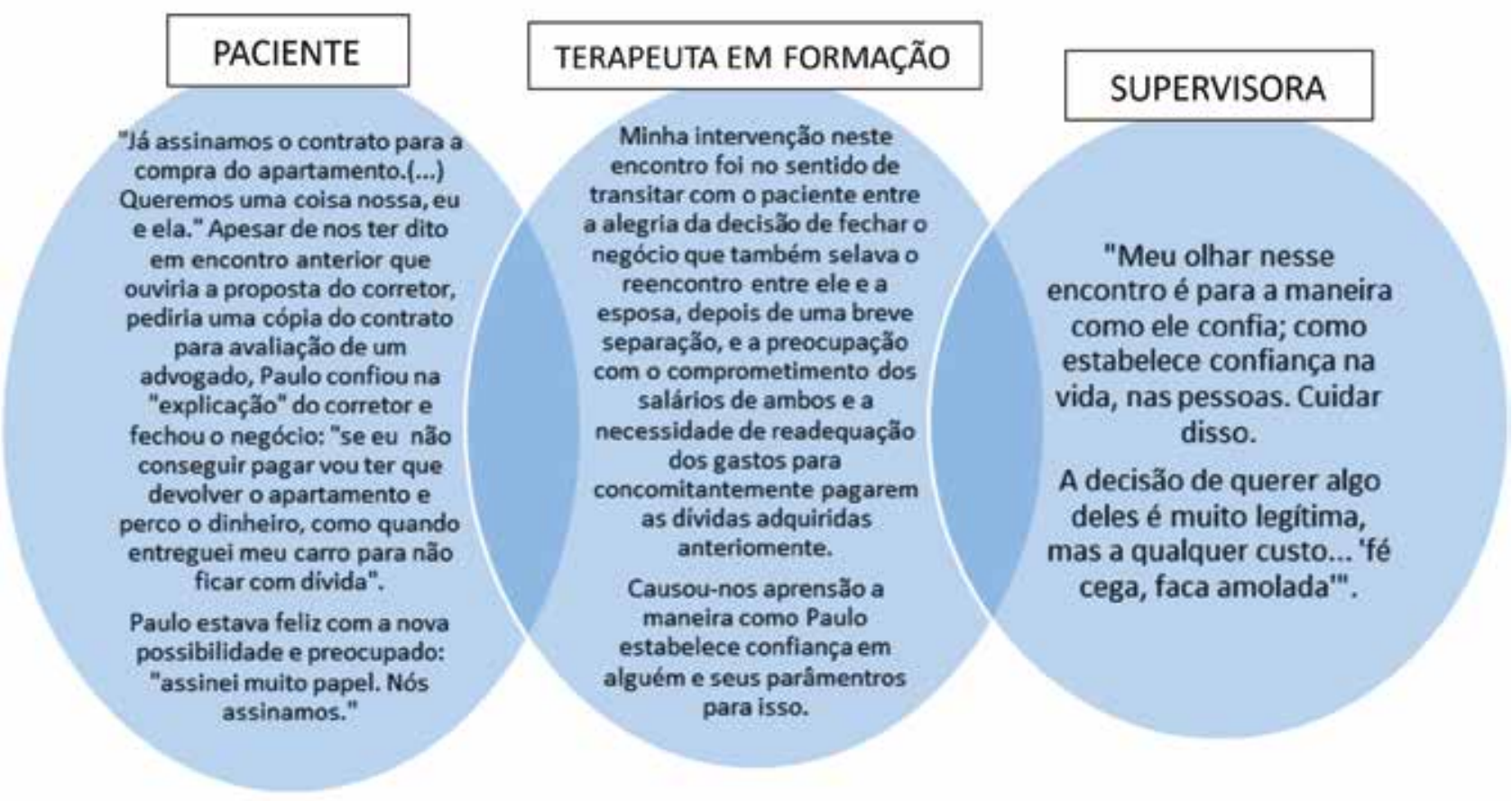

Paulo, em encontros anteriores, descrevia sua dificuldade para comunicar o que sentia e como se sentia em relação às pessoas em sua vida pessoal, especialmente à esposa, e também aos colegas no trabalho. Receoso de ser mal interpretado, incompreendido ou mesmo punido, vinha descrevendo repetidamente as mesmas situações em psicoterapia.

Este encontro foi selecionado para análise porque, em retrospectiva, significa para nós um momento importante no processo psicoterápico. Vivenciá-lo nos mostrou que a repetição em psicoterapia, longe de ser uma responsabilidade exclusiva do paciente, também pode não significar falta de repertório ou simplesmente estagnação no mesmo ponto.

Paulo descreveu, em vários encontros anteriores, seus problemas financeiros, sua falta de mobilidade e como havia chegado a tal situação. Já tinha nos contado que, apesar de tais limitações, desejava investir em um imóvel próprio e sair da casa da sogra, onde morava. Em virtude das dívidas atuais e das experiências de perda anteriores, Paulo parecia bastante cauteloso, mostrando certa desconfiança em relação ao discurso do vendedor, que lhe apresentara uma proposta. Disse-nos que estava disposto a consultar um advogado e que verificaria com cuidado as condições do contrato que poderia vir a assinar.

Paulo chegava à clínica com meia hora de antecedência e o encontrávamos sempre conversando com a secretária. Ao chegarmos, percebemos que ele falava sobre o assunto que havia sido o tema central de nosso encontro anterior. Ao ser chamado, o paciente finaliza a conversa com a secretária, em tom mais elevado, dizendo “- Agora é ver como vamos dar conta!"

Ao entrar no setting e se sentar, ele tinha um riso contido que se misturava aos tiques. Contou-nos que havia fechado o negócio. Surpresas, procurávamos compreender de que maneira isso tinha se dado, uma vez que, no encontro anterior, ele parecia bastante inseguro para dar tal passo. Fomos conversando e procurando identificar o que havia acontecido para que ele mudasse de ideia e fechasse o negócio. Ao contrário do que esperávamos, fomos percebendo que as condições para o negócio haviam se tornado ainda mais restritivas do que as que ele tinha nos apresentado na semana passada: não tinham conseguido obter o subsídio total do imóvel junto ao banco e não tinham nem ideia de quanto seria a taxa de construção, uma vez que estavam adquirindo o apartamento ainda na planta.

O método fenomenológico, cuja ênfase é descritiva, implica estar concentrado(a) à história contada para além de seus conteúdos e aspectos causais, atento(a) a um contexto generativo complexo e paradoxal e, ao mesmo tempo, ao que acontece no encontro com o paciente desde a primeira troca de olhares, quando o recebemos: os gestos, a disposição dos corpos e não somente ao que é dito verbalmente. Neste encontro, o paciente estava contente e ansioso, e seus tiques fizeram-no retesar braços e pescoço, sorrir involuntariamente e piscar mais enfaticamente.

Neste encontro, percebemos com nitidez que havia uma aproximação com Paulo. Conforme íamos conversando, intelectivamente achávamos que Paulo tinha sido precipitado, impulsivo, ao fechar o negócio, porque o que ele nos apresentava como uma facilidade, oferecida pelo vendedor, não se tratava nem mesmo de uma bonificação para que o negócio fosse fechado, como tinha sido dito ao paciente. Ao mesmo tempo, sentíamos ali, na presença de Paulo, que ele estava preocupado e contente com a decisão que havia tomado, e percebíamos em nós uma discreta satisfação ao encontrá-lo 
nesse lugar. Conforme nosso método, para poder encontrá-lo efetivamente naquele momento, precisamos parentetizar a ideia, ou ainda, o julgamento de que ele havia sido precipitado ao fazer o negócio, e olhar de novo para o que ele expressava ali e como aquilo nos afetava. Apesar de surpresas, não nos sentíamos apreensivas, e percebíamos o paciente lidando com o paradoxo de estar "preocupado" por ter assinado "mais de uns vinte papel" e sonhando com tudo que o corretor disse que o empreendimento terá em termos de estrutura e benfeitorias. Ele transitava e nós?

Colocar entre parênteses o juízo, para poder ouvir o que Paulo dizia, da forma como descrevia, foi um esforço compreensivo que também levou a parentetizar a maneira como ele confia, e o que considerávamos ingenuidade. Foi preciso olhar de novo, e de novo, procurando reconhecer o que se apresentava em nosso encontro. Congruentes, garantimos abertura para o novo e conseguimos dizer a ele por meio de uma hermenêutica confirmatória: "Sentimos aqui, Paulo, que você está preocupado sim, com esse passo importante que vocês deram, e que a experiência de ter que devolver o carro, que foi muito sofrida para você, não o impediu de fazer esse novo negócio. Faz sentido para você? Depois de ter vivido aquela situação, você poderia não querer mais passar por algo parecido; se acomodar, não se comprometer mais... O que você acha?"

Arriscamo-nos a fazer uma hermenêutica con- firmatória nesse momento de saída do parêntese, em busca de um sentido partilhado a ser confirmado pelo outro. Nós nos lançamos empaticamente ao encontro com o paciente, testemunhando-o, em busca da vivência e da confirmação de uma nova possibilidade de sentido. Paulo confirma a interpretação e reafirma também nossa percepção de que a aquisição do imóvel sela seu reencontro com a esposa: “- Nós conversamos e queremos uma coisa nossa! Eu quero e ela também quer."

Conforme traduz Merleau-Ponty (1945/1999) há na fala uma camada superficial que quando ultrapassada chega ao sentido vivo (primário), um sentido que se concretiza na linguagem. Em outras palavras, há um certo silêncio que procura se romper e que só o "é" quando expresso. O contingente paradoxal do sentido é o silêncio. Para Amatuzzi (2010), esse é o caso típico de uma pessoa que procura terapia: "seus falares parecem bloqueados no secundário, um falar-sobre que não tem desencadeado um viver, mas que já por ser um tatear (quando em terapia), aponta para algo vivo" (Amatuzzi, 2010, p.37). Assim permanecemos nesse tatear conjunto que buscava reconhecer que sentido tinha para Paulo arriscar novos modos de ser mediados por nossa presença que, por sua vez, transitava entre o temor por suas decisões e o vislumbre de potência em suas relações interpessoais, especialmente, a marital.

$21^{\circ}$ Encontro: $13 / 11 / 2017$

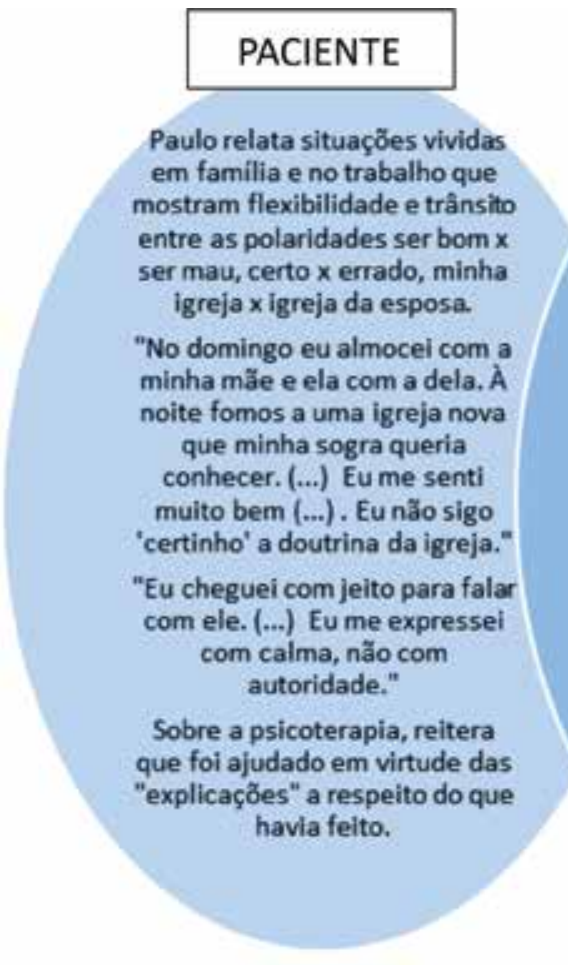

As supervisões anteriores foram fundamentais para ampliar nosso olhar sobre o que estava sendo vivido no encontro, valorizar e suplantar as expectativas de que o paciente compreendesse "como nós" o processo que estávamos compartilhando. Em alguns momentos, neste último encontro, ainda insistimos
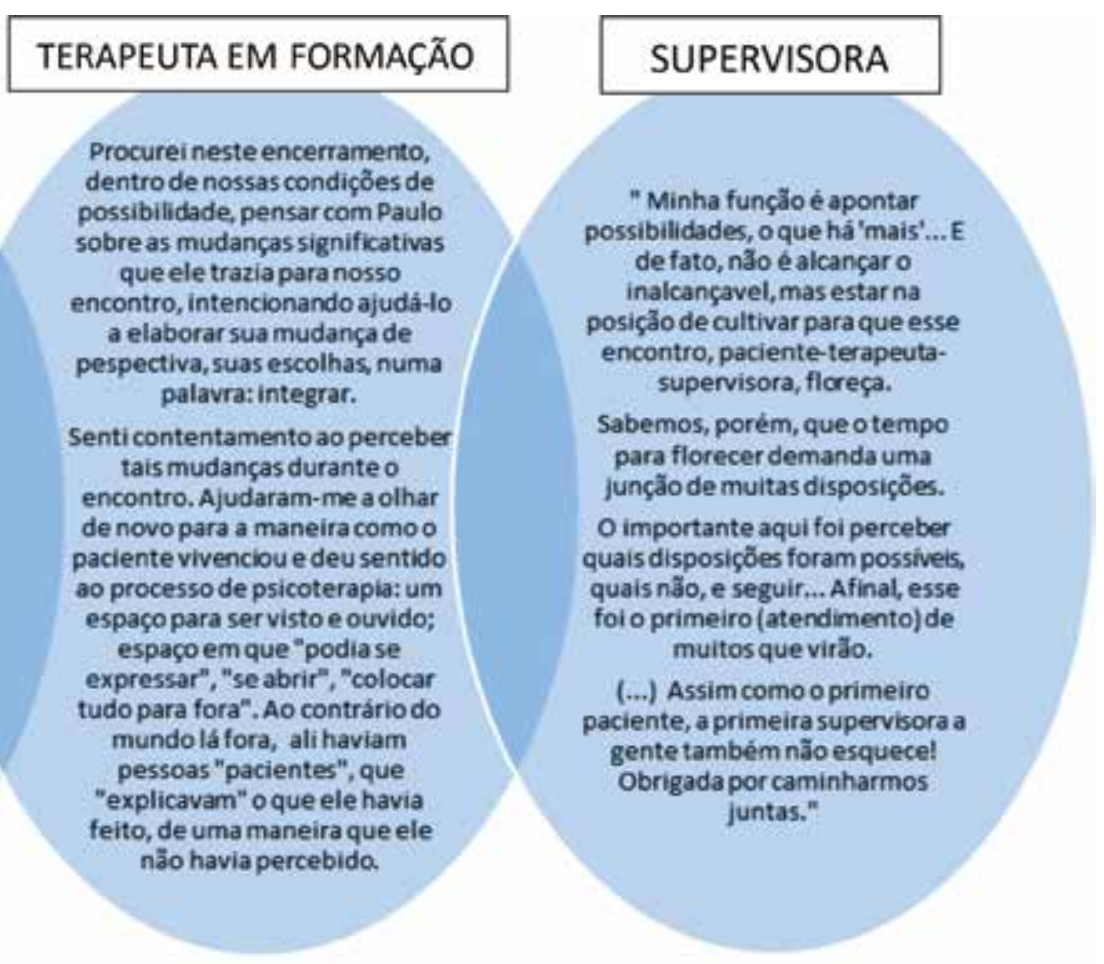

com o paciente, convidando-o a sentir-pensar sobre o quanto havíamos alargado as possibilidades entre "o certo e o errado", que ele trazia com veemência no início do processo, e como ele nos parecia mais flexível em suas escolhas. É importantíssimo notar que em nossa compreensão, caminhávamos de acordo com o 
que preconiza o método fenomenológico, mobilizando o paciente em direção a sentidos novos do trabalho realizado. Entretanto, no mesmo instante que falávamos, desconfiávamos de nossas palavras, que ao serem proferidas, perdiam força. Fomos nos dando conta de que tentávamos impor um sentido que garantisse ao encerramento um final que remediasse nossos desencontros anteriores. Deste modo, desconsiderávamos, assim, a fala do paciente que apontava para um direcionamento durante o processo, e também sua experiência, o que promovia mais desencontro.

A supervisão sobre esta última sessão nos convida a temporalizar, (o tempo de quem importa?), e chama a atenção para um outro aspecto importante, além da tentativa de garantir um sentido para todo o processo: "o tempo para florescer demanda uma junção de muitas disposições”. A supervisora nos estimula a pensar no tempo do paciente e no nosso tempo na clínica, a cada um dos encontros e sobretudo, neste último. Era preciso respeitar o tempo do paciente, e o que foi possível mobilizar, transformar e elaborar a respeito das mudanças.

E nossa mudança de postura acontece justamente quando confiamos naquilo que sentimos-pensamos durante o encontro - e que não é, portanto, uma intelectualização ou tentativa de instrumentalização. Olhamos de novo para o encontro, para o que estava sendo dito ali, naquele momento, como aquilo ressoa em nós e como essa experiência se traduz em significado. Somos, então, capazes de voltar e seguir ali, junto, sobrepondo o que vivenciamos aos cálculos ou expectativas para esse encerramento da psicoterapia.

Rogers diz que quando aceitamos a nós mesmos, as relações se tornam reais e passam a ter "o caráter apaixonante de serem vitais e significativas" (Rogers, 1975, p.29). Quando sou capaz de aceitar o fato de estar irritada ou aborrecida com um(a) paciente, então também estou mais apta, ainda conforme Rogers, a aceitar as reações que minha atitude provoca. Torno-me capaz de aceitar a mudança da experiência e dos sentimentos que podem, então, acontecer tanto nele(a) como também em mim. Rogers afirma que as relações reais tendem mais a se modificar do que a permanecerem estáveis, estáticas.

Aceitar verdadeiramente o paciente não é nada fácil, não só quando ele encara a vida e seus problemas de forma completamente diversa da nossa, mas sobretudo quando diverge na compreensão da experiência que realizamos juntos. A aceitação incondicional não surge facilmente, e como disse a supervisora, "há que ser cultivada" neste e em encontros futuros.

Ao abordar o processo terapêutico, que nos torna mais próximos de quem somos, Rogers ainda considera uma outra forma de compreendê-lo: como uma aprendizagem para o paciente. No caso de pessoas em formação, e mesmo para os que já angariaram experiência no diálogo fenomenológico, consideramos que tal aprendizagem se dá no mesmo nível para todos, mas com diferentes focos e por meio de uma polissemia em que se encontram e se dão a conhecer. E de qual aprendizagem Rogers está falando? De "um tipo estranho de aprendizagem" que quase nunca se nota por sua complexidade e, "mesmo quando atingiu o grau mais profundo, nunca parece adaptar-se bem aos símbolos verbais" (Rogers, 1975, p.181). É desse "o que há a mais..." que a supervisora nos fala e que não pode ser ensinado, uma vez que sua essência é o caráter de porvir.

Para Rogers (1975), ao mesmo tempo que tal aprendizagem assume formas simples, implica descobertas que possuem um imenso significado em patamares difíceis de definir. Seria essa a dificuldade de Paulo significar a mudança que já parecia capaz de exercer, apontada pela supervisora? Seria também a nossa dificuldade, como terapeutas, para olhar de novo para essas formas simples e prenhas de significados valiosos, como: "Eu almocei com a minha mãe e ela com a dela”, "Eu não sigo 'certinho' a doutrina da Igreja”, "Eu cheguei com jeito para falar com ele (...) me expressei com calma, não com autoridade", "Eu vindo aqui e vocês me 'explicando' o que tinha que ser feito, (...) sei que grande parte depende de mim, mas vocês me ajudaram a ter melhoras"?

A aprendizagem significativa que ocorre na terapia, não pode ser ensinada a quem quer que seja, simplesmente porque o ensino a destruiria. Nesse sentido, retomando as descrições, talvez possamos compreender os apontamentos da supervisora relativamente a forma como recorremos a uma postura professoral, e o quanto ela coloca em risco um processo de autodescoberta que poderíamos ter facilitado, durante o processo psicoterápico. Nas palavras de Rogers:

Eu podia ensinar a um paciente que, para ele, é uma segurança ser ele próprio, que assimilar livremente os seus sentimentos não é perigoso, etc. Quanto mais eu lhe ensinasse isso, menos ele aprenderia de uma forma significativa, experiencial e auto-apropriante. Kierkegaard considera esta última forma de aprendizagem como a verdadeira subjetividade, sublinhando que não pode haver nenhuma comunicação direta, nem indireta. O máximo que uma pessoa pode fazer por outra é criar determinadas condições que tornam possível esta forma de aprendizagem. (Rogers, 1975, p.182).

Consideramos esse aspecto da clínica de inspiração humanista, em diálogo fenomenológicos, transgressor, na medida que objetiva amenizar o sofrimento do paciente por meio de relações que revitalizam o humano, em um processo que procura se estabelecer de forma horizontal, cada vez mais autêntico e respeitoso ao tempo e ao espaço do outro. $\mathrm{O}$ trabalho que realizamos promove mudanças que não seriam passíveis de explicação, ensinamento ou teorização, uma vez que se trata do exercício de ser 
cada vez mais quem se é, graças a condição ontológica de existirmos com o outro, considerando a singularidade de cada um terapeutas-paciente-supervisora, de cada sessão, e da totalidade que nos envolve. Trata-se de formar um vínculo terapêutico e do reconhecimento de "um certo silêncio", que se cumpre e é arrastado pela fala quando encontra no outro uma testemunha (Merleau-Ponty 1945; 1999). Permanece com isso, um movimento de intenção significativa, e não um conceito estanque, que alimenta nosso trabalho na clínica e na pesquisa fenomenológica.

\section{Conclusão}

Este trabalho de pesquisa teve como propósito dar visibilidade ao processo de formação do(a) psicoterapeuta em supervisão por meio da aproximação com o vivido e sua expressão, junto às versões de sentido, tanto no setting terapêutico com o paciente na clínica-escola, quanto nos encontros de supervisão.

Nossa tentativa de resposta, sempre provisória e à espera de um outro olhar, se deu neste trabalho em dois níveis da análise: descritivo, apresentado através de círculos interseccionados, que trazem as falas do paciente, do terapeuta e da supervisora; e compreensivo, num prolongamento do esforço de análise do que ocorreu na sessão, através da reflexão sobre seu sentido.

Selecionamos para a análise a descrição do primeiro encontro com Paulo e sua respectiva supervisão, com o propósito de evidenciar como a supervisão nos ajuda a "olhar de novo" para o vivido no encontro, num processo indistinto e amorfo entre o sentir, o pensar e o agir. Nesse momento, há um convite ao esforço árduo e profundo de revisitar quem se é e como nos dispomos ao encontro vivido.

A descrição do segundo encontro selecionado está relacionada ao meio do processo terapêutico, que teve a duração total de oito meses. Tratou-se de um momento delicado para as terapeutas em formação, em que o paciente, com hesitação, começava a tomar consciência de sua responsabilidade pessoal quanto aos problemas, e a experimentar sentimentos no presente, com desconfiança e medo.

A terceira e última descrição selecionada refere-se ao final do processo, no qual vão surgindo novos sentimentos-pensamentos, flexibilidade para o transitar e ocupar lugares, cujo acesso anteriormente era bastante limitado, senão bloqueado. Há o vislumbre de que novas maneiras de ser brotando para ambos: paciente e terapeuta.

Compreendemos que a descrição da primeira experiência de atendimento na clínica escola, bem como o esforço compreensivo que se segue, deu visibilidade ao processo e mostrou a junção de disposições necessárias, e não necessariamente existentes, para que houvesse um "encontro". A análise convida a um tatear ininterrupto entre temporalidades distintas que se dispõem a estarem juntas no processo terapêutico e na pesquisa.
Desta maneira, por se tratar de uma compreensão do vivido, as considerações estendem-se para além da relação terapêutica, em busca de outros interlocutores vivos que mantenham o diálogo sobre tal experiência. É um permanente exercício de retorno "às coisas mesmas", um movimento de resgatar nossa capacidade eidética dativa, de dar-se a conhecer. Ao mesmo tempo, trata-se de revisitar momentos de medo, espanto, descoberta e contentamento, vividos em conjunto e em um arranjo contemporâneo que elege a clínica como espaço de cuidado. Um espaço e um tempo que carecem de permanente reinvenção.

O esforço compreensivo convidou à reflexão sobre o significado da prática psicoterápica e a formação de psicoterapeutas, em diálogos com a epistemologia fenomenológica com enfoque humanista. Tencionamos que ele possa contribuir no sentido de fomentar outras significações e perspectivas sobre a clínica.

\section{Referências}

Amarante, P. (1995). Novos sujeitos, novos direitos: o debate sobre a reforma psiquiátrica no Brasil. Cad. Saúde Públ. 11(3), 491-494. Recuperado em outubro de 2017, de https://dx.doi. org/10.1590/S0102-311X1995000300024

Amatuzzi, M. M. (2009). Psicologia fenomenológica: uma aproximação teórica humanista. Estudos de Psicologia, 26(1), 93100. Recuperado em setembro de 2017, de http://www.scielo.br/scielo.php?script =sci_arttext\&pi$\mathrm{d}=$ S0103-166X2009000100010\&lng $=$ pt\&nrm $=$ iso

Amatuzzi, M. M., Solymos, G. M. B., Ando, C., Bruscagin, C. B. S., \& Costabile, C. (1991). O sentido-que-faz-sentido: uma pesquisa fenomenológica no processo terapêutico. Psicologia: Teoria e Pesquisa, Brasília, 7(1), 1-12. Recuperado em outubro de 2017, de https://revistaptp.unb.br/ index.php/ptp/article/download/1408/402

Amatuzzi. (2010). Por uma psicologia humana. Campinas, SP: Editora Alínea.

Barreira, C. R. A. \& Ranieri, L. P. (2013). Aplicação de contribuições de Edith Stein à sistematização de pesquisa fenomenológica em psicologia: a entrevista como fonte de acesso às vivências. Em M. Mahfoud \& M. Massami, (Org.), Edith Stein e a Psicologia: teoria e pesquisa (pp. 449466). Belo Horizonte: Artesã.

Basaglia, F. (1969; 2010). Escritos Selecionados em saúde mental e reforma psiquiátrica. Rio de Janeiro: Garamond. 
Boris, G. D. J. B. (2008). Versões de sentido: um instrumento fenomenológico-existencial para a supervisão de psicoterapeutas iniciantes. Psicologia Clínica, 20(1), 165180. Recuperado em outubro de 2017, de http://www.scielo.br/scielo.php?script=sci_arttext\&pi$\mathrm{d}=$ S0103-56652008000100011\&lng $=$ en\&nrm $=$ iso

Brasil (2013). Resolução no 466 de dezembro de 2012. Conselho Nacional de Saúde. Recuperado em novembro de 2019, de https:/conselho. saude.gov.br/resolucoes/2012/Reso466.pdf

Buber, M. (2001). Eu e Tu. São Paulo: Centauro Editora.

Giorgi, A. (2008) Sobre o método fenomenológico utilizado como modo de pesquisa qualitativa nas ciências humanas: teoria, prática e avaliação. Em J. Poupart, J. Deslauriers, \& L. Groulx. A pesquisa qualitativa: enfoques epistemológicos e metodológicos. 386-409. Petrópolis, RJ: Vozes.

Gomes, W.B. \& Castro, T. G. de. (2010). Clínica fenomenológica: do método de pesquisa para a prática psicoterapêutica. Psicologia: Teoria e Pesquisa, 26 (n. especial) 81-93. Recuperado em outubro de 2017, de http://www.scielo.br/scielo.php?script=sci_arttext\&pi$\mathrm{d}=$ S0102-37722010000500007\&lng =en\&nrm =isso

Goto, T. A. (2008). Introdução à Psicologia Fenomenológica: a nova psicologia de Edmund Husserl. São Paulo: Paulus.

Husserl, E. (1907;1958). A idéia da fenomenologia. Rio de Janeiro: Edições 70.

Husserl, E. (1913; 2006). Idéias para uma fenomenologia pura e para uma filosofia fenomenológica: introdução geral à fenomenologia pura. São Paulo: Idéias \& Letras.

Husserl, E. (1926-38; 2012). A crise das ciências europeias e a fenomenologia transcendental: uma introdução à filosofia fenomenológica. Rio de Janeiro: Forense Universitária.

Merleau-Ponty, M. (1999). Fenomenologia da Percepção. São Paulo: Martins Fontes.

Moreira, V. \& Correia, K. C. R. (2016). A experiência vivida por psicoterapeutas e clientes em psicoterapia de grupo na clínica humanista-fenomenológica: uma pesquisa fenomenológica. Psicol. USP, 27(3), 531541. Recuperado em outubro de 2017, de http://www.scielo.br/scielo.php?script=sci_arttext\&pi$\mathrm{d}=$ S0103-65642016000300531\&lng $=$ en\&nrm $=$ iso

Moreira, V. (2013). Revisitando as psicoterapias humanistas. São Paulo: Intermeios.
Rocha, R. M. G. (2015). Análise compreensiva de uma nova modalidade de trabalho na saúde: o Grupo Comunitário de Saúde Mental. (Tese de Doutorado em Psicologia). Faculdade de Filosofia, Ciências e Letras de Ribeirão Preto, Universidade de São Paulo, Ribeirão Preto.

Rogers, C. R. (1975). Tornar-se pessoa. São Paulo: Livraria Martins Fontes Editora Ltda.

Rogers, C. R. (1978) Grupos de Encontro. São Paulo: Martins Fontes.

Rosenberg, R. L. (1987). Aconselhamento psicológico centrado na pessoa. São Paulo: EPU.

Tavora, M. T. (2002). Um modelo de supervisão clínica na formação do estudante de psicologia: a experiência da UFC. Psicologia em Estudo, 7(1), 121-130. Recuperado em outubro de 2017, de http://www.scielo.br/pdf/pe/v7n1/v7n1a13

Rita Martins Godoy Rocha (orcid.org/00000002-5539-0304). Doutora em Psicologia pela Universidade de São Paulo. Docente e supervisora clínica na Universidade de Araraquara. Email: rmgrraddi@uniara.edu.br

Andréa de Souza Túbero (orcid.org/0000-0001-56990443). Psicóloga pela Universidade de Araraquara. Email: deatubero@gmail.com

Recebido em 17.12.2018 Primeira decisão editorial em 28.06.2019 Segunda decisão editorial em 17.10.2019 Aceito em 31.03.2020 